\title{
PENGARUH KEPATUHAN KONSUMSI TABLET FE TERHADAP KADAR HAEMOGLOBIN IBU HAMIL
}

\author{
Effect Of Adherence To Fe Tablet Consumption To Increase Hemoglobin Levels
}

\author{
${ }^{1}$ Wini Hadiyani, ${ }^{2)}$ Viena Yunidha \\ ${ }^{1,2}$ Program Studi S1 KeperawatanSekolah Tinggi Ilmu Keperawatan PPNI Jawa Barat \\ winhad@yahoo.com
}

\begin{abstract}
ABSTRAK
Pendahuluan: Defisiensi zat besi pada ibu hamil dapat menyebabkan menurunnya kadar hemoglobin yang menyebabkan berkurangnya oksigen untuk memenuhi kebutuhan organ-organ vital pada ibu dan janin. Konsumsi zat besi dapat membantu untuk mencegah meningkatnya kondisi anemia pada ibu hamil. Penelitian ini bertujuan untuk mengetahui pengaruh kepatuhan konsumsi tablet $\mathrm{Fe}$ terhadap peningkatan kadar haemoglobin. Metodologi: Pelaksanaan penelitian menggunakan desain kohort perspektif. Populasi dalam penelitian ini adalah ibu hamil yang mengalami anemia selama 6 bulan terakhir di wilayah kerja UPT Puskesmas Cibuntu sebanyak 31 orang. Hasil penelitian menunjukkan adanya pengaruh yang signifikan dari kepatuhan konsumsi tablet Fe terhadap peningkatan kadar hemoglobin dengan nilai p-value 0.003 (<0.05). Kesimpulan kepatuhan dalam mengkonsumsi tablet $\mathrm{Fe}$ dapat mempengaruhi kadar hemoglobin, dan disarankan khususnya bagi Puskesmas Cibuntu umumnya bagi tenaga kesehatan lainnya agar lebih mengoptimalkan pengawasan konsumsi tablet zat besi pada ibu hamil yang mengalami anemia Kata kunci :, Hamil, Hemoglobin, Tablet-Fe
\end{abstract}

\section{ABSTRACT}

Introduction: Deficiency of Fe in pregnant women can lead haemoglobin decreased levels which can reduced oxygen carrying capacity for the needs of vital organs in the mother and fetus. Fe consumption can help to prevent the increased incidence of anemia in pregnant women. The Aim of this study was to determine the effect of adherence to Fe tablet consumption to increase hemoglobin levels. Methods: This research used analytic survey research with perspective cohort design. The population in this study were pregnant women who experienced anemia during the last 6 months in the working area of UPT Puskesmas Cibuntu as many as 31 people. The results showed significant influence of compliance of Fe tablet consumption to increase hemoglobin levels with p-value $0.003(<0.05)$. Conclussion we can conclude that compliance in Fe tablets may affect hemoglobin level, and especially recommended for Puskesmas Cibuntu generally for other health workers to optimalize the supervision of pregnant women who have anemia in taking iron tablets.

Keywords:, Hemoglobin, Pregnant, Tablet-Fe 


\section{PENDAHULUAN}

Anemia pada ibu hamil sering terjadi di negara berkembang salah satunya adalah di Indonesia. Anemia dapat meningkatkan risiko terjadi kematian ibu hamil mendekati 4 kali lebih tinggi jika dibandingkan ibu hamil yang tidak anemia. Tingginya prevalensi anemia pada ibu hamil di Indonesia rata-rata 63,5\% (Saifudin, 2006). Anemia merupakan salah satu penyebab kematian pada ibu hamil di Indonesia. Angka kematian Ibu (AKI) di Indonesia mencapai 228/100.000 kelahiran hidup. Kondisi ini menempatkan Indonesia sebagai salah satu negara dengan AKI tertinggi di Asia. (DepKes RI, 2012)

Anemia pada ibu hamil mengakibatkan menurunnya kadar hemoglobin $(\mathrm{Hb})$ sehingga berkurangnya pemenuhan oksigen untuk kebutuhan organ-organ vital pada ibu dan janin. Menurunnya kadar $\mathrm{Hb}$ ini diakibatkan asupan zat gizi yang kurang sehingga terhambat pembentukan komponen $\mathrm{Hb}$ terutama zat besi (Fe). Anemia yang dikarenakan kekurangan zat besi (Fe) merupakan anemia yang paling banyak ditemukan di Indonesia (Depkes RI 2013). Direktorat Kesehatan Keluarga mendapatkan data bahwa penyebab kematian ibu sebanyak 40\% diakibatkan perdarahan. Kondisi anemia pada ibu hamil akan memperberat risiko perdarahan.

Anemia defisiensi zat besi pada ibu
hamil dapat ditanggulangi dengan
memberikan tablet penambah darah $(60 \mathrm{mg}$
elemental besi dan 250 ug asam folat. Beberapa factor yang dapat menurunkan kejadian anemia, menurut Niven (2002) diantaranya adalah anjuran terhadap kepatuhan konsumsi tablet Fe. Konsumsi tablet $\mathrm{Fe}$ dapat mengobati dan mencegah anemia akibat kekurangan zat besi memiliki efektivitas yang terbatas terutama karena ketidakpatuhan faktor konsumsi makanan sebagai penghambat penyerapan zat besi.. Menurut penelitian yang dilakukan oleh Nils
Milman pada tahun 2011 di Denmark, kebutuhan zat besi pada ibu hamil sangat tinggi dan tidak dapat dipenuhi oleh intervensi diet saja. Meningkatnya kebutuhan $\mathrm{Fe}$ berfungsi untuk meningkatkan volume darah, massa jaringan tubuh ibu, dan pertumbuhan janin

Program kesehatan ibu hamil selain memeriksakan kehamilan, diantaranya adalah minum pil tambah darah sertiap hari selama 90 hari. Kebutuhan zat besi ibu hamil 50\% lebih banyak yaitu sekitar $39 \mathrm{mg} / \mathrm{hari}$ dibandingkan dengan masa sebelum hamil yang hanya membutuhkan $26 \mathrm{mg} / \mathrm{hari}$. Salah satu pemenuhan kebutuhan zat besi akan terpenuhi jika ibu hamil patuh dalam mengkonsumsi tablet Fe. Kepatuhan didefinisikan sebagai jumlah tablet yang dikonsumsi untuk total yang dianjurkan selama periode waktu tertentu.

Hasil studi pendahuluan peneliti mewawancarai 10 orang ibu hamil , 7 diantaranya tidak patuh dalam mengkonsumsi tablet Fe. Hal ini menunjukkan bahwa salah satu faktor penyumbang kejadian anemia pada ibu dipengaruhi oleh kesadaran dan kepatuhan dalam mengkonsumsi tablet Fe. Ketepatan dosis, cara konsumsi dan waktu konsumsi tablet $\mathrm{Fe}$ perhari merupakan dasar dari kepatuhan. Pencegahan Anemia yang efektif dengan asupan tablet $\mathrm{Fe}$ yang dilengkapi dengan kandungan asam folat. Pemberian Tablet Fe merupakan cara efektif karena adanya kandungan besi yang dilengkapi asam folat. Menurut (Arief, 2008) dengan mengkonsumsi tablet $\mathrm{Fe}$ secara rutin selama 30 hari maka akan meningkatkan kadar hemoglobin sebesar $1 \mathrm{gr} / \mathrm{dl}$.

\section{METODE PENELITIAN}

Penelitian ini merupakan penelitian quasi eksperimen, tujuannya adalah untuk mengetahui pengaruh kepatuhan konsumsi tablet zat besi $(\mathrm{Fe})$ terhadap peningkatan kadar hemoglobin pada ibu hamil di wilayah kerja UPT Puskesmas Cibuntu dengan 
menggunakan pendekatan Kohort Perspektif dimana dalam pengambilan data peneliti hanya melakukan survey dengan adanya rentang waktu antara pre dan post. Sampel penelitian sebanyak 31 ibu hamil yang mengalami anemia ( $\mathrm{Hb}<11 \mathrm{gr} / \mathrm{dl})$. Pengambilan responden menggunakan tehnik purposive sampling. Instrumen yang digunakan berupa lembar observasi checklist $(\sqrt{)}$ yang berisi tabel jadwal dalam mengkonsumsi tablet zat besi $(\mathrm{Fe})$ dan alat ukur untuk mengetahui kadar hemoglobin (sahli). Tekhnik pengumpulan data yang dilakukan adalah melakukan perijinan, setelah itu peneliti melakukan pengumpulan data dengan cara membagikan lembar checklist serta melakukan pemeriksaan kadar hemoglobin dalam satu waktu kepada setiap responden kemudian setelah 30 hari dilakukan hal yang sama pada responden yang sama.

\section{HASIL}

\section{Analisis Univariat}

a. Gambaran Kadar Hemoglobin Sebelum Observasi

Tabel 1 Distribusi Frekuensi Kadar Hemoglobin Sebelum Observasi

\begin{tabular}{ccc}
\hline Kadar HB & Frekuensi & \% \\
\hline$<9.5$ & 2 & 6.45 \\
$9.6-9.9$ & 10 & 32.26 \\
$10.1-10.5$ & 6 & 19.35 \\
$10.6-10.9$ & 13 & 41.94 \\
\hline Total & 31 & 100.0 \\
\hline
\end{tabular}

\section{b. Gambaran Peningkatan Hemoglobin Setelah Observasi}

Tabel 2 Distribusi Frekuensi Kadar Hemoglobin Setelah Observasi

\begin{tabular}{ccc}
\hline Kadar HB & Frekuensi & \% \\
\hline$<9.5$ & - & - \\
$9.6-9.9$ & - & - \\
$10.1-10.5$ & 9 & 29.03 \\
$10.6-10.9$ & 2 & 6.45 \\
$11-11.5$ & 14 & 45.16 \\
$11.6-11.9$ & 3 & 9.68 \\
$12-12.5$ & 3 & 9.68 \\
\hline Total & 31 & 100.0 \\
\hline
\end{tabular}

\section{c. Gambaran Kepatuhan Sebelum Observasi}

Tabel 3 Distribusi Frekuensi Kepatuhan Mengkonsumsi Tablet Zat Besi Sebelum Observasi

\begin{tabular}{lll}
\hline Kepatuhan & Frekuensi & $\mathbf{\%}$ \\
\hline Tidak Patuh & $\mathbf{2 0}$ & $\mathbf{6 4 . 5}$ \\
Patuh & 11 & 35.5 \\
\hline Total & 31 & 100 \\
\hline
\end{tabular}

\section{d. Gambaran Kepatuhan Setelah Observasi}

Tabel 4 Distribusi Frekuensi Kepatuhan Mengkonsumsi Tablet Zat Besi Setelah Observasi

\begin{tabular}{ccc}
\hline Kepatuhan & Frekuensi & \% \\
\hline Tidak Patuh & 9 & 29.0 \\
Patuh & $\mathbf{2 2}$ & $\mathbf{7 1 . 0}$ \\
\hline Total & 31 & 100.0 \\
\hline
\end{tabular}

\section{Analisis Bivariat}

a) Perbedaan kadar hemoglobin sebelum dan setelah observasi

Tabel 5 Perbedaan kadar hemoglobin sebelum dan setelah observasi

\begin{tabular}{lcccccc}
\hline & & \multicolumn{2}{c}{ Sebelum } & \multicolumn{2}{c}{ Setelah } & \\
\cline { 3 - 6 } & N & Mean & SD & Mean & SD & Pvalue \\
\cline { 4 - 6 } $\begin{array}{l}\text { Kadar } \\
\text { Hb }\end{array}$ & 31 & 10.32 & 0.6 & 11.1 & 0.5 & 0.000 \\
\hline
\end{tabular}




\section{b) Pengaruh tingkat kepatuhan terhadap kadar hemoglobin}

Tabel 6 Pengaruh tingkat kepatuhan terhadap kadar hemoglobin

\begin{tabular}{|c|c|c|c|c|c|c|c|}
\hline & \multicolumn{7}{|c|}{ Kadar Hemoglobin } \\
\hline & \multicolumn{3}{|c|}{ Sebelum } & \multicolumn{4}{|c|}{ Setelah } \\
\hline & $\begin{array}{c}\text { Mea } \\
\text { n }\end{array}$ & SD & $\mathbf{n}$ & $\begin{array}{c}\text { Mea } \\
\mathbf{n}\end{array}$ & $\begin{array}{l}\text { S } \\
\mathbf{D}\end{array}$ & $\mathbf{n}$ & $\begin{array}{c}p \\
\text { valu } \\
\text { e }\end{array}$ \\
\hline Patuh & $\begin{array}{c}10 \\
6\end{array}$ & $\begin{array}{c}0.2 \\
2\end{array}$ & $\begin{array}{l}1 \\
1\end{array}$ & $\begin{array}{c}11 . \\
3\end{array}$ & $\begin{array}{c}0.4 \\
8\end{array}$ & $\begin{array}{l}2 \\
2\end{array}$ & 0.00 \\
\hline Tidak Patuh & $\begin{array}{c}10 . \\
1\end{array}$ & $\begin{array}{c}0.5 \\
2 \\
\end{array}$ & $\begin{array}{l}2 \\
0 \\
\end{array}$ & $\begin{array}{c}10 . \\
6\end{array}$ & $\begin{array}{c}0.5 \\
6\end{array}$ & 9 & 3 \\
\hline
\end{tabular}

\section{PEMBAHASAN}

\section{Pembahasan Univariat}

Hasil analisis univariat mengenai gambaran kadar hemoglobin sebelum observasi menunjukkan bahwa seluruhnya ibu hamil mengalami anemia ( $\mathrm{Hb}<11 \mathrm{gr} / \mathrm{dl})$, hampir setengahnya kadar hemoglobin adalah 10.6 $10.9 \mathrm{gr} / \mathrm{dl}$. sebanyak 13 orang (41.94\%). Berlandaskan pada teori Arief, (2008) jika konsentrasi anemia kurang dari 10,5-11,0 gram/dl selama kehamilan merupakan indikasi anemia. Kekurangan zat besi yang disebabkan anemia menyebabkan terganggunya pertumbuhan sel-sel tubuh termasuk sel-sel otak, sehingga dapat mengakibatkan perdarahan sebelum dan selama persalinan, lahir premature, berat badan lahir rendah, keguguran pada ibu hamil, yang paling buruk adalah menyebabkan kematian pada ibu dan janinnya. Kebutuhan zat besi pada ibu hamil dengan anemia tidak mampu memenuhi kebutuhan oksigen pada janinnya secara optimal sehingga beresiko terjadinya gangguan kematangan organ-organ tubuh janin. Perdarahan saat melahirkan pada keadaan anemia sangat beresiko mudahnya terjadi shock hipovolemia dan resiko kematian akan lebih besar. Berdasarkan hal tersebut maka peneliti menyimpulkan bahwa kadar hemoglobin rendah dapat menyebabkan berbagai gangguan bagi ibu hamil dan janinnya.

Hasil analisis univariat mengenai gambaran tingkat kepatuhan sebelum observasi menunjukkan bahwa lebih dari setengah ibu hamil tidak patuh dalam mengkonsumsi tablet zat besi yaitu sebanyak 20 orang $(63.5 \%)$. Ketidakpatuhan ibu hamil dalam konsumsi $\mathrm{Fe}$ dipengaruhi beberapa faktor yaitu adanya rasa mual bahkan sampai muntah setelah menkonsumsi tablet fe, malas dan lupa. Hal ini sejalan dengan teori Niven, (2002) yaitu faktor sikap dan motivasi. Sikap menentukan ibu hamil dalam menjaga kehamilannya salah satunya memperhatikan kebutuhan zat besi yang penting saat kehamilan. Motivasi yaitu perilaku yang timbul diakibatkan dorongan dari dalam diri seseorang dan diikuti dengan kesadaran dan kemauan untuk mengkonsumsi tablet zat besi (Fe) tanpa terpengaruh adanya efek samping dari tablet zat besi $(\mathrm{Fe})$ itu sendiri.

Tingkat ketidakpatuhan dipengaruhi oleh pemahaman yang kurang terhadap informasi yang diberikan. Informasi yang kurang difahami akan mengakibatkan, kualitas interaksi yang kurang diminati, kurang empati, kurang kejelasan, kurang pentingnya keterampilan interpersonal dalam memacu kepatuhan (Nurbaity, 2004).

Peningkatan kadar hemoglobin setelah observasi selama 30 hari menunjukkan bahwa sebagian besar ibu hamil dengan hemoglobin < $11 \mathrm{gr} / \mathrm{dl}$ mengalami peningkatan kadar hemoglobin sebesar $0.2-1.5 \mathrm{gr} / \mathrm{dl}$. Peningkatan kadar hemoglobin tersebut sejalan dengan penelitian yang dilakukan Nils Milman di Denmark yang manyatakan bahwa peningkatan kadar hemoglobin selama minimal 30 hari dan mengkonsumsi tablet besi yaitu sebesar $1-1.4 \mathrm{gr} / \mathrm{dl}$.

Peningkatan kadar hemoglobin dipengaruhi beberapa faktor diantaranya adalah nutrisi dan tablet zat besi yang dikonsumsi setiap hari kemudian pendidikan 
kesehatan sehingga menjadi tau manfaat mengkonsumsi gizi seimbang dan tablet zat besi. Hal ini sejalan dengan teori (Tarwoto, 2013) yang menyatakan bahwa penatalaksanaan anemia yaitu terdiri dari pemberian unsur zat besi yang terdapat dalam makanan, diantaranya daging, telor, ikan dan sayuran hijau. Cara lain untuk meningkatkan kadar $\mathrm{Hb}$ dengan pemberian suplemen besi yang mengandung $60 \mathrm{mg} \mathrm{Fe}$ dan 0,25 asam folat dianggap paling cocok bagi ibu hamil. Konsumsi tablet yang diberikan setara dengan $200 \mathrm{mg}$ ferosulfat, yang diberikan 90 tablet sampai 42 minggu selama kehamilan dan setelah melahirkan, dosis tablet Fe untuk pencegahan $1 \times 1$ tablet dan $3 \times 1$ tablet untuk dosis pengobatan (bila $\mathrm{Hb}<11$ gram/dl). Pada saat jeda makan dimana lambung tidak banyak makanan saat yang tepat mengkonsumsi tablet $\mathrm{Fe}$, karena kondisi ini menyebabkan zat besi akan mudah diserap. Selain itu factor pengetahuan pun harus ditingkankan. Pemberian pendidikan kesehatan pada ibu hamil yang meliputi pengetahuan tentang anemia serta makanan yang dapat meningkatkan asupan zat besi. Berdasarkan hal tersebut peneliti menyimpulkan bahwa peningkatan kadar hemoglobin dapat terjadi jika ada motivasi, pendidikan kesehatan mengenai pentingnya mengkonsumsi tablet zat besi dan zat gizi sesuai kebutuhan serta sarana (lembar checklist $(\sqrt{ })$ ) yang diberikan kepada ibu hamil yang mengalami anemia.

Kepatuhan setelah observasi menunjukkan bahwa lebih dari setengah ibu hamil patuh dalam mengkonsumsi tablet zat besi yaitu sebanyak 22 orang (71\%). Berbeda dengan sebelum observasi bahwa ibu hamil yang tidak patuh lebih banyak daripada yang patuh. Hal ini dipengaruhi beberapa faktor, salah satunya dengan pemberian lembar checklist $(\sqrt{ })$ untuk jadwal mengkonsumsi tablet zat besi yang harus diisi setiap hari.

Berdasarkan teori yang berkaitan dengan faktor perilaku yang dikembangkan oleh Laurence Green (Notoatmodjo,2010), perilaku kepatuhan didasari oleh 3 faktor utama, yaitu : (1) predisposing factor. Perilaku kesehatan seseorang akan dipengaruhi oleh pengetahuan dan sikap masyarakat terhadap kesehatan, kepercayaan, nilai, keyakinan, dan sebagainya (2) enabling factor, yaitu tersedianya fasilitas-fasilitas atau sarana kesehatan akan memungkinkan terjadinya perilaku kesehatan, (3) reinforcing factor, yaitu perubahan perilaku didukung adanya sikap dan praktik petugas kesehatan maupun tokoh masyarakat, dan pihak keluarga.

Peran petugas kesehatan sangat penting dalam mengarahkan ibu hamil untuk mematuhi peraturan minum tablet zat besi $(\mathrm{Fe})$. Tablet Fe akan bermanfaat jika ibu hamil minimal mendapatkan 90 tablet secara teratur (Depkes, 2007). Berdasarkan hal tersebut peneliti dapat menyimpulkan bahwa setelah diberikan lembar checklist $(\sqrt{ })$, meningkatkan kepatuhan ibu hamil dalam mengkonsumsi Fe..

\section{Pembahasan Bivariat}

Hasil analisis bivariat perbedaan kadar hemoglobin sebelum dan setelah observasi dengan hasil uji statistik menggunakan $t$ test dengan pvalue 0.000 yang berarti terdapat perbedaan yang signifikan dengan kadar hemoglobim sebesar $0.78 \mathrm{mg} / \mathrm{dl}$ setelah 30 hari observasi. Berlandaskan pada teori (Saifudin, 2002) pemberian tablet Fe 60mg/hari dapat meningkatkan kadar $\mathrm{Hb}$ sebanyak $1 \mathrm{gr} / \mathrm{dl}$ perbulan. Hal ini sesuai dengan orogram nasional menganjurkan asupan kombinasi $60 \mathrm{mg}$ besi dan 50 nano gram asam folat untuk profilaksis anemia. Arief (2008) menjelaskan penanggulangan anemia pada ibu hamil merupakan hal penting karena sel darah merah menurun atau menurunnya hemoglobin, menjadikan kurangnya oksigen untuk memenuhi kebutuhan organ-organ vital pada ibu hamil dan janin. Rendahnya jumlah oksigen dalam darah berdampak kompensasi tubuh dengan memacu jantung terus menerus sehingga mengakibatkan gagal jantung dan komplikasi lain seperti preeklampsia. Kejadian 
anemia pada ibu hamil, bervariasi tergantung pada lokasi geografis dan sosial ekonomi. Berdasarkan hal tersebut diatas maka peneliti menyimpulkan bahwa perbedaan yang terjadi pada kadar hemoglobin dipengaruhi oleh pemberian lembar checklist $(\sqrt{ })$ karena dengan diberikan lembar checklist $(\sqrt{ })$ maka ibu hamil akan mengisi dan mengkonsumsi tablet secara teratur yang dapat meningkatkan kadar hemoglobin sebesar.

Pengaruh tingkat kepatuhan terhadap kadar hemoglobin diperoleh nilai pvalue < alfa $(0.003<0.05)$, sehingga terdapat pengaruh yang sgnifikan antara kepatuhan konsumsi tablet zat besi terhadap peningkatan kadar $\mathrm{Hb}$. Ada beberapa cara yang dapat dilakukan untuk mengetahui tingkat kepatuhan diantaranya, keputusan tenaga kesehatan berdasarkan hasil pemeriksaan, pengamatan jadwal pengobatan yang telah ditetapkan yaitu minum tablet zat besi $(\mathrm{Fe})$ sesuai dosis dan diminum satu kali sehari pada malam hari, penilaian terhadap tujuan pengobatan, perhitungan jumlah tablet atau pil pada akhir pengobatan (Susetyowati, 2001). Berdasarkan hal tersebut peneliti menyimpulkan bahwa peningkatan kadar hemoglobin dapat dipengauhi oleh tingkat kepatuhan ibu hamil dalam mengkonsumsi tablet zat besi

\section{KESIMPULAN DAN SARAN}

\section{Kesimpulan}

Setelah dilakukan penelitian maka dapat ditarik kesimpulan sebagai berikut

1. Adanya perbedaan mean kadar hemoglobin sebelum dan setelah diberikan lembar checklist $(\sqrt{ })$ yaitu sebelum $10.32 \mathrm{gr} / \mathrm{dl}$ dan setelah $11.1 \mathrm{gr} / \mathrm{dl}$.

2. Terdapat pengaruh kepatuhan konsumsi tablet zat besi terhadap peningkatan kadar hemoglobin setelah diberikan lembar checklist $(\sqrt{ })$ pvalue 0.003 .

\section{Saran}

Khususnya bagi Puskesmas dan umumnya bagi tenaga kesehatan lainnya diharapkan agar lebih mengotimalkan pengawasan minum tablet Fe pada ibu hamil yaitu:

a) Ibu hamil diberikan lembar checklist $(\sqrt{ })$ yang harus diisi selama mengkonsumsi tablet Fe (30 hari), karena berdasarkan hasil penelitian yang dilakukan di wilayah kerja UPT Puskesmas Cibuntu terbukti bahwa dengan diberikan lembar checklist $(\sqrt{ })$ tingkat kepatuhan menjadi meningkat b) Pemeriksaan kembali kadar hemoglobin setelah diberikan lembar checklist $(\sqrt{ })$

\section{DAFTAR PUSTAKA}

Arief,Nurhaeni. 2008. Panduan Lengkap Kehamilan dan Kelahiran Sehat. Yogyakarta: Dianloka

Arikunto,Suharsimi. 2010. Prosedur Penelitian Suatu Pendekatan Praktik. Jakarta: Rineka Cipta

Choundhury, Nuzhat Et Al. 2012. Relative Efficacy Of Micronutrient Powders Versus Iron-Folic Acid Tablets In Controlling Anemia In Women In The Second Trimester Of Pregnancy. The United Kingdom University Journal, UK diakses 04-02-2014 18:11

Dharma, Kelana Kusuma. 2012. Metodologi Penelitian Keperawatan. Jakarta: Trans Info Media

Dinas Kesehatan Kota Bandung. 2013. Bina

Pelayanan Kesehatan KIA 2013. Bandung

Dinas Kesehatan Kota Bandung. 2013. Laporan LB3-Gizi, Dinas Kesehatan Kota Bandung Tahun 2011. Bandung

Dinas Kesehatan Provinsi Jawa Barat. 2012. Profil Kesehatan Provinsi Jawa Barat. Bandung 
Hidayat, A, Aziz. 2013. Metode Penelitian Keperawatan dan Teknik Analisis Data. Jakarta: Salemba Medika Kementrian Kesehatan Indonesia. 2013. Profil Kesehatan Indonesia 2012. Jakarta: Kementrian Kesehatan RI. Pusat Data dan Informasi.

Lindstrom Emma, et al. 2010. Prevalence of anemia and micronutrient deficiencies in early pregnancy in rural Bangladesh, the MINIMat trial. Bangladesh.

Milman, Nils. 2011. Ironi in Pregnancy How Do We Secure an Appropriate Iron Status in the Mother and Child. Departments of Clinical Biochemistry and Obstetrics, Næstved Hospital, Næstved. Denmark diakses pada 0402-2014 18:10
Neil, Niven. 2002. Psikologi Kesehatan. Jakarta: EGC

Notoatmodjo, Soekidjo. 2010. Metodologi Penelitian Kesehatan. Jakarta: Rineka Cipta.

Nursalam. 2008. Konsep dan Penerapan Metode Penelitian Ilmu Keperawatan. Jakarta: Salemba Medika

Rachmat, Mochamad. 2012. Buku Ajar Biostatistika. Jakarta: EGC

Tarwoto. Wasnidar. 2013. Buku saku Anemia Pada Ibu Hamil, Konsep dan Penatalaksanaan. Jakarta: Trans Info Media 